\title{
CORRELATION BETWEEN FOLLICULAR FLUID COMPOSITION AND OOCYTES RECOVERY RATE, AND IN VITRO MATURATION
}

\author{
I.T. El-Ratel ${ }^{1}$, M. M. El-Moghazy ${ }^{2}$ and A.E. Abdel-Khalek ${ }^{3}$
}

1- Poultry Production Department, Faculty of Agriculture, Damietta University, Egypt, 2- Animal Production Department, Faculty of Agriculture, Damietta University, Egypt, 3- Animal Production Department, Faculty of Agriculture, Mansoura University, Egypt.

Corresponding Author: ibrahim.talat81@yahoo.com

This study aimed to evaluate the correlation between follicular fluid composition collected from small or large follicles of ovaries with or without corpus luteum and rates of recovery, quality and in vitro maturation of bovine oocytes. Ovaries with and without corpus luteum were collected from slaughtered cows. On each ovarian surface, all visible follicles were measured and classified into small $(\mathrm{SF} \leq 8 \mathrm{~mm})$ and large $(\mathrm{LF}>8 \mathrm{~mm})$ follicles. Follicular fluid and oocytes were aspirated from small and large follicles of ovaries with and without corpus luteum. Oocytes were classified and only acceptable oocytes (good quality) were in vitro matured. Concentration of progesterone, estradiol-17 $\beta$, testosterone and lactic acid in follicular fluid were determined. Results showed that follicular fluid of large follicles of ovaries without corpus luteum (LFCL) showed significantly $(\mathrm{P}<0.05)$ the highest estradiol-17 $\beta$ and testosterone concentrations $(128.38$ and $29.83 \mathrm{ng} / \mathrm{ml})$, the lowest lactic acid concentration $(86.5 \mathrm{mg} / \mathrm{dl})$ and lower progesterone concentration $(46.16 \mathrm{ng} / \mathrm{ml})$. Also, oocytes of LFCL showed significantly $(\mathrm{P}<0.05)$ the best recovery rate $(85.8 \%)$, acceptable quality (81.97\%), and cytoplasmic (80.97\%) and nuclear maturation $(79.18 \%)$ rates. Among the follicular fluid contents, only testosterone level correlated $(\mathrm{P}<0.001)$ negatively with lactic acid content $(\mathrm{r}=-0.792)$. Follicular fluid concentration of lactic acid showed negative correlation $(\mathrm{P}<0.001)$ with each of recovery $(\mathrm{r}=-0.741)$, acceptable quality $(\mathrm{r}=-0.919)$, cytoplasmic maturation $(\mathrm{r}=-0.934)$ and nuclear maturation $(\mathrm{r}=-0.906)$ rate. Results of stepwise multiple regression of oocyte quality on follicular fluid composition indicated that lactic acid concentration was the $1^{\text {st }}$ independent factor entering the multiple regression equation $\left(\mathrm{R}^{2}=84.4 \%\right)$, and about $74.9 \%$ of the variation in oocyte quality was caused by variation in testosterone concentration $\left(2^{\text {nd }}\right.$ independent factor).

In conclusion, choosing ovarian status (without corpus luteum) and follicular size (large) is the $1^{\text {st }}$ step for obtaining higher successful maturation rate of oocytes recovered from slaughtered cows based on oocytes quality.

Keywords: Cattle, corpus luteum, follicles, diameter, follicular fluid, maturation 